\title{
Estimation of Solar Energy Influx to the Sea in the Light of Fast Satellite Technique Development
}

\author{
Adam Krężel and Katarzyna Bradtke \\ University of Gdańsk, Institute of Oceanography \\ Poland
}

\section{Introduction}

"Solar radiation plays a fundamental role in the marine environment. It supplies the energy that drives thermodynamic and photochemical processes in the sea, including the heating of waters, their stratification and movement, and their evaporation, also the warming of the atmosphere, the photosynthesis of the organic matter essential for the maintenance of life and the functioning of marine ecosystems, and the photo-oxidation of marine pollutants" (Dera \& Woźniak, 2010). The amount of solar energy reaching the sea surface can be determined by means of direct measurements or calculations with the use of various models of different precision and complexity. Due to obvious reasons, systematic, direct measurements in the area of oceans and seas with the spatial resolution satisfactory for monitoring and analysis of several processes like the ones mentioned above, are impossible in practice. On the other hand, credibility of modelling strongly depends on model's input data - their quality and time resolution. The most difficult task in calculating the solar energy stream at the sea surface using a model is to obtain its momentary value. It is caused by the lack of precise information on the components of the Earth's atmosphere influencing the solar radiation along its way from the upper boundary to the sea surface. The most important of these components is the cloudiness but other parameters like aerosol optical thickness, the content of water vapour or ozone should also be taken into account.

Fast development of satellite technique in the field of Earth observation and monitoring makes it possible to get more or less precise information about the atmosphere properties which play an important role in solar energy transfer to the Earth's surface in every place and further into the sea.

The idea of our consideration is to provide a broad overview of contemporary space-borne sources of data necessary to increase the accuracy of simple models of solar energy transfer through the Earth's atmosphere, especially over the oceans and seas.

\section{Solar radiation}

The Sun, a medium-sized star, produces energy as a result of thermo-nuclear processes in its interior. Recently it has been estimated to be about $3.9 \times 10^{26} \mathrm{~W}$. This power is radiated into 
space uniformly in all directions. Fundamental physical laws tell us that the intensity of this radiation decreases as the inverse square of the distance from the source. At the mean distance from the Sun to the Earth this energy, in total, is known as solar "constant". Its spectral distribution is close to the radiation of a blackbody at the temperature about $6000 \mathrm{~K}$ but, due to different processes inside and on the surface of the Sun, this dependence is not as smooth as it results from Planck's law. It is the reason that the first step to obtain the spectrum of solar energy at the Earth's surface is to determine, by means of measurements, its value in the upper frontier of the atmosphere (TOA $\left.{ }^{1}\right)$. Along the path to the Earth's surface, the incoming solar radiation undergoes the wave dependent processes of absorption and scattering. As a result, a part of it is reflected back to space, another part is absorbed by the elements of the air and the rest reaches the surface. It consists of two components: the direct radiation from the Sun and the diffuse radiation from the atmosphere. Under cloudless conditions the relationship between them depends on the position of the Sun in the sky - the higher the Sun elevation angle the higher the difference between them. In Fig. 1 one can see an exemplary spectral distribution of the solar irradiance at the sea level calculated for real cloudless atmosphere over the Baltic Sea near the solar noon on 2011-06-21 at 11:00 UTC (the Sun elevation angle was about 59 ${ }^{\circ}$ ). The evident differences between the shapes of the extraterrestrial and other curves are due to the light absorption and scattering processes which depend on some components of the air. The most important of these processes are: molecular scattering, absorption by water vapour, ozone, and other atmospheric gases as well as attenuation (absorption and scattering) by atmospheric aerosols. The strength of these processes depends to a different degree on concentration and distribution in the atmosphere of the accounted components. The most spectacular consequences of strong deviations of some components' concentrations from their common state are known as the global warming (due to the increase in the greenhouse gases concentration - the water vapour is one of them) or the "ozone hole" - the effect of decreased ozone concentration in the so-called ozone layer. The importance of such phenomena for life on our planet causes the need of their continuous monitoring. It is done by the networks of ground-based measuring stations like for instance WMO-Global Atmospheric Watch observing system, Network for the Detection Atmospheric Composition Change, NOAA Earth System Research Laboratory/Global Monitoring Division etc. It is obvious, that such networks do not cover the whole Earth's surface and the shortage of information concerns in particular the atmosphere over the oceans and seas (Fig. 2). It is also true for the solar radiation monitoring. New opportunities in the area of global monitoring of the Earth's atmosphere and surface arose due to fast development of the space-based measurements. The satellite-based instruments provide regular views of any place of the Earth. Despite the fact that such measurements must still be supplemented by the ground-based measurements, it enables fast progress in broadening our knowledge in this area.

The traditional way of getting the information on the solar energy reaching the Earth's surface in the case of lack of direct measurements was to use more or less complicated models of light transmission in the atmosphere. To run the model it is necessary to gather the input data which characterize actual state of the atmospheric components important from this point of view, namely: the atmospheric pressure and humidity, aerosol optical

1 Top of the atmosphere 
thickness (AOT), content of ozone, and cloudiness. One can do it using routine measurements or values obtained by interpolation between them, results of calculations with the use of other (meteorological) models, climatological values, models of the Earth's atmosphere etc. The space-based measurements of AOT, content of ozone, and water vapour in the column of the atmosphere, and cloudiness used as the input data can rise the precision of such models to a significant degree. To check this thesis we shall compare the results of calculations of solar energy input at the Baltic Sea surface performed with a simple model for irradiance on the horizontal plane at the Earth's surface presented in part 3.

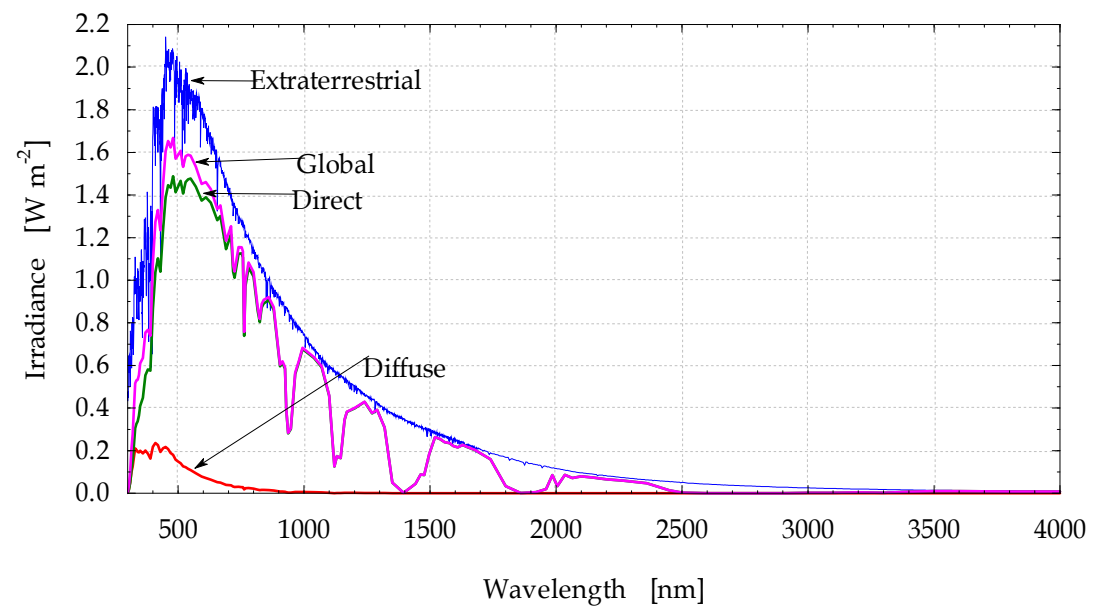

Fig. 1. Direct, diffuse, and total solar irradiance for a real cloudless atmosphere over the Baltic Sea (long. $18.82^{\circ} \mathrm{E}$, lat. $54.60^{\circ} \mathrm{N}$ ) on $2011-06-21$ near solar noon (11:00 UTC)

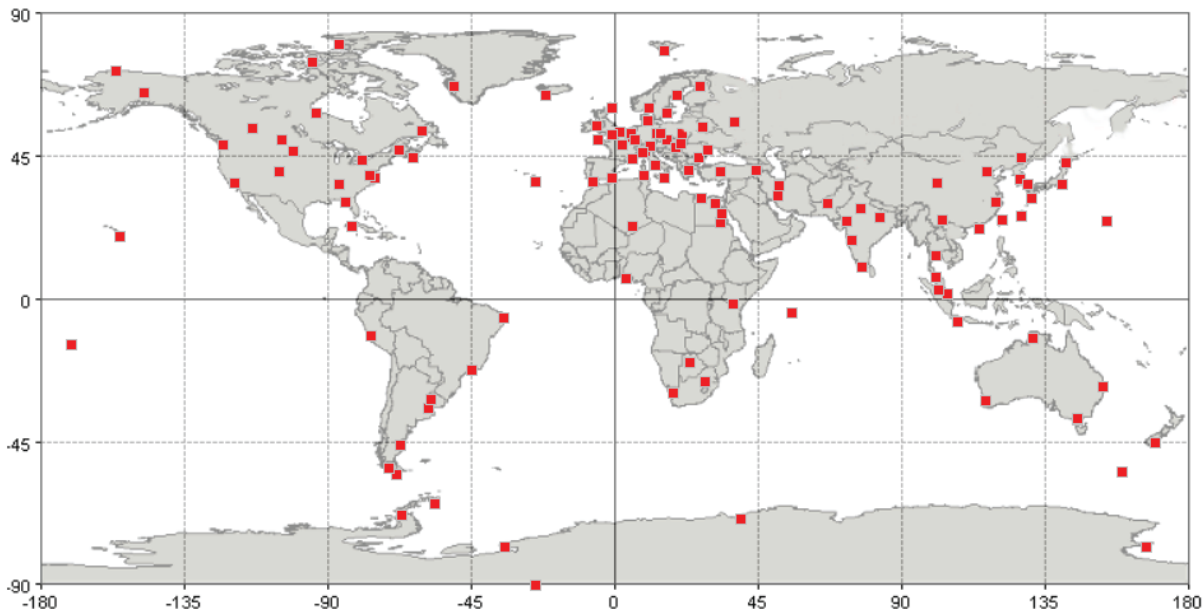

Fig. 2. The 132 WMO-GAW stations measuring total ozone with Dobson and/or Brewer spectrophotometers (GCOS-GAW ..., 2007) 


\section{Model}

There are many ways of calculation of light transmission through the Earth's atmosphere from complicated models like developed in the 1970's LOWTRAN ${ }^{2}$ or MODTRAN ${ }^{3}$ to the simplest ones that take into account the dependence of the incoming radiation only on one variable (e.g. mean cloudiness). To compare the influence of different sources of the input data on the results of solar irradiance calculations at the sea level we have chosen a simple model proposed by Bird and Riordan (1986) with several later modifications (Krężel \& Kozłowski, 2001; Krężel et al., 2008). The model enables one to calculate easily the contribution of the main constituents to the total attenuation of the solar radiation on its way from the upper frontier of the Earth's atmosphere to the sea surface.

\subsection{Calculation algorithms of direct solar radiation}

Considering the most important processes of interaction of the solar radiation passing to the sea surface with the atmosphere constituents, the direct irradiance of the horizontal area by the solar beam incidence (at the sea surface) could be expressed as:

$$
E_{s}(\lambda)=\cos \vartheta \frac{F_{s}(\lambda)}{\beta^{2}} T_{R}(\lambda) \cdot T_{a}(\lambda) \cdot T_{w v}(\lambda) \cdot T_{O_{3}}(\lambda) \cdot T_{G}(\lambda)
$$

where: $\lambda$ - the wavelength; $\vartheta$ - the solar zenith angle, $F_{s}(\lambda)$ - the spectral density of the solar constant; $\beta=R_{S} / R$ - the factor defining the annual variability of the distance between the Earth and the Sun $\left(R\right.$ and $R_{S}$ - actual and mean distance between the Earth and the Sun, respectively); $T_{R}(\lambda) \ldots T_{G}(\lambda)$ - the functions of the atmosphere transmission describing irradiance attenuation in the processes of molecular scattering, scattering and absorption by aerosols and absorption by water vapour, ozone and the most important constant gaseous components of the atmosphere, respectively.

In the algorithms the presented $F_{s}(\lambda)$ values and the coefficients of absorption of water vapour $a_{w v}(\lambda)$, ozone $a_{O 3}(\lambda)$ and constant gaseous components of the atmosphere $a_{G}(\lambda)$ for 122 wavelengths were accepted after Neckel and Labs (1981). The algorithms allowing to determine $\beta$ value and the solar zenith angle at given place and any time were taken from Michalsky (1988).

To calculate the succeeding transmission functions one should know the so-called relative optical atmospheric mass M. At the sea level the expression of Kasten \& Young (1989) considering curvature of the atmosphere was applied:

$$
M=\left[\sin \gamma_{s}+0.50572 \cdot\left(\frac{180 \gamma_{s}}{\pi}-6.07995\right)^{-1.6364}\right]^{-1}
$$

where: the solar altitude $\gamma_{s}=\frac{\pi}{2}-\vartheta$ is expressed in radians

\footnotetext{
2 Low-resolution propagation model and computer code for predicting atmospheric transmittance and background radiance from 350 to $40,000 \mathrm{~cm}^{-1}$ at a resolution of $20 \mathrm{~cm}^{-1}$

${ }^{3}$ MODerate resolution atmospheric TRANsmission - computer program designed to model atmospheric propagation of electromagnetic radiation from 100 to $50,000 \mathrm{~cm}^{-1}$ spectral range at a resolution of $0.2 \mathrm{~cm}^{-1}$.
} 
In the calculations of the atmospheric transmission functions (1) the following algorithms were used:

a. molecular scattering (Kneizys et al., 1980):

$$
T_{r}(\lambda)=\exp \left[\frac{-M^{\prime}}{\lambda^{4} \cdot\left(115.6406-\frac{1.335}{\lambda^{2}}\right)}\right]
$$

where: $M^{\prime}=M \cdot\left(P / P_{0}\right), P$ - the atmospheric pressure $[\mathrm{hPa}], P_{0}=1013 \mathrm{hPa}$; the wavelength $\lambda$ is expressed in $[\mu \mathrm{m}]$.

b. aerosol attenuation:

The influence of aerosols on the light transmission is taken into consideration by determination of so-called aerosol optical thickness of the atmosphere (AOT):

$$
\operatorname{AOT}(\lambda) \equiv \tau_{a}(\lambda)=-M \ln T_{a}(\lambda)
$$

where $T_{a}$ - the light transmission through the cloudless atmosphere resulting from the presence of aerosols. For determination of AOT the classical formula of Angström (1963) was used:

$$
\operatorname{AOT}(\lambda)=\beta_{n} \lambda^{-b_{n}}
$$

For the Baltic Sea area the values of $b_{n}$ and $\beta_{n}$ coefficients, typical for the regions of relatively low atmosphere dustiness, were applied, i.e. $\beta_{n}=0.12$ and $b_{n}=1.0274$ for $\lambda<0.5 \mu \mathrm{m}$ and 1.2060 for $\lambda>0.5 \mu \mathrm{m}$.

c. absorption by ozone is calculated from the formula:

$$
T_{0}(\lambda)=\exp \left[-a_{0}(\lambda) \cdot O_{3} \cdot M_{0}\right]
$$

where the relative optical mass of the atmospheric ozone $M_{0}$ was defined after Iqbal (1983):

$$
M_{0}=\frac{\left(1+\frac{h_{0}}{6370}\right)}{\left(\cos ^{2} \vartheta+\frac{2 \cdot h_{0}}{6370}\right)^{0.5}}
$$

and $h_{0}=22 \mathrm{~km}$ was accepted as the mean height of the maximum ozone concentration. The mean nine-year (1997-2005) $\mathrm{O}_{3}$ values, defining the ozone concentration in an atmospheric air column of a unit base area, for latitudes $50^{\circ}-60^{\circ} \mathrm{N}$ in individual months are shown in Table 1 .

\begin{tabular}{c|c|c|c|c|c|c|c|c|c|c|c|c} 
Month & Jan & Feb & Mar & Apr & May & Jun & Jul & Aug & Sep & Oct & Nov & Dec \\
\hline $\mathrm{O}_{3}[\mathrm{~cm}]$ & 0.37 & 0.39 & 0.40 & 0.39 & 0.38 & 0.36 & 0.33 & 0.32 & 0.31 & 0.30 & 0.32 & 0.35
\end{tabular}

Table 1. Mean ozone concentration in the atmosphere in latitudes $50^{\circ}-60^{\circ} \mathrm{N}$ (TOMS, 2007) 
d. absorption by water vapour; the expression presented by Leckner (1978) was used:

$$
T_{w}(\lambda)=\exp \left[\frac{-0.2385 \cdot a_{w}(\lambda) \cdot W \cdot M}{\left[1+20.07 \cdot a_{w}(\lambda) \cdot W \cdot M\right]^{0.45}}\right]
$$

where $W$ is the water vapour mass in an atmospheric air column of unit base area and is calculated from the data on the water vapour pressure $e_{0}$ at the sea level, according to the relation (Reitan, 1960):

$$
W=\left(0.123+0.152 \cdot e_{0}\right) \frac{P}{1000}
$$

where: $e_{0}$ and $P$ are expressed in $[\mathrm{hPa}]$.

e. absorption by the other significant components of the atmosphere; the expression from the paper by Leckner (1978) was applied:

$$
T_{u}(\lambda)=\exp \left[\frac{-1.41 \cdot a_{u}(\lambda) \cdot M^{\prime}}{\left[1+118.3 \cdot a_{u}(\lambda) \cdot M^{\prime}\right]^{0.45}}\right]
$$

In the model for determination of illumination at the sea level by direct solar radiation, the algorithms (1) to (10) were used. The source of the highest errors is undoubtedly the way of determination of solar radiation attenuation by aerosols. This error is the greatest when the instantaneous illumination values are calculated and it decreases with the extension of averaging period.

\subsection{Calculation algorithms of scattered radiation}

Algorithms presented in the paper of Bird and Riordan (1986) were used in the model construction.

It should be assumed that scattered radiation incident on the horizontal area is the total of three components:

$$
E_{d}(\lambda)=E_{d R}(\lambda)+E_{d a}(\lambda)+E_{d g}(\lambda)
$$

- resulting from molecular scattering $E_{d R}(\lambda)$,

- $\quad$ resulting from aerosol attenuation $E_{d a}(\lambda)$ and

- $\quad$ resulting from multiple reflection between the sea (land) surface and the atmosphere $E_{d g}(\lambda)$.

These components have the following forms:

$$
\begin{gathered}
E_{d R}(\lambda)=F_{s}(\lambda) \cdot \beta^{-2} \cdot \cos \vartheta \cdot T_{O_{3}}(\lambda) \cdot T_{G}(\lambda) \cdot T_{w v}(\lambda) \cdot T_{a a}(\lambda)\left[1-T_{R}(\lambda)^{0.95}\right] \cdot 0.5 \\
E_{d a}(\lambda)=F_{s}(\lambda) \cdot \beta^{-2} \cdot \cos \vartheta \cdot T_{O_{3}}(\lambda) \cdot T_{G}(\lambda) \cdot T_{w v}(\lambda) \cdot T_{a a}(\lambda) T_{R}(\lambda)^{1.5} \cdot\left[1-T_{a s}(\lambda)\right] \cdot F \\
E_{d g}(\lambda)=\frac{\left[F_{s}(\lambda) \cos \vartheta+E_{d R}+E_{d a}(\lambda)\right] r_{s}(\lambda) r_{g}(\lambda)}{1-r_{s}(\lambda) r_{g}(\lambda)}
\end{gathered}
$$


$T_{a a}(\lambda)$ and $T_{a s}(\lambda)$ are transmission functions determined by aerosol absorption and scattering, respectively:

$$
\begin{gathered}
T_{a s}(\lambda)=\exp \left[-\omega_{0}(\lambda) \cdot \tau_{a}(\lambda) \cdot M\right] \\
T_{a a}(\lambda)=\exp \left\{-\left[1-\omega_{0}(\lambda)\right] \cdot \tau_{a}(\lambda) \cdot M\right\}
\end{gathered}
$$

where: $\omega_{0}(\lambda)$ is the so-called single scattering albedo (from definition $\omega_{0}=\frac{b}{a+b} ; b$ and $a$ are the volume coefficients of scattering and absorption, respectively), $\tau_{a}(\lambda)$ - the optical thickness of the atmosphere resulting from aerosol occurrence. For its determination formulas (4) and (5) were used.

It is assumed here that molecular scattering and scattering by aerosols are independent and also, that half of the irradiance is directed towards the lower hemisphere in the process of Rayleigh`s scattering, regardless of actual direction of incident solar radiation.

The dependence of single scattering albedo on the wavelength is defined by the relation:

$$
\omega_{0}(\lambda)=\omega_{0}(0.4 \mu \mathrm{m}) \cdot \exp \left[-\omega^{\prime}\left(\ln \frac{\lambda}{0.4}\right)^{2}\right]
$$

where: $\omega_{0}(0.4 \mu \mathrm{m})$ - the single scattering albedo for the wavelength of $0.4 \mu \mathrm{m}, \omega^{\prime}-$ the wavelength variation factor.

In the regions of relatively low atmospheric turbidity $\omega_{0}(0.4)=0.945$ and $\omega^{\prime}=0.095, r_{g}(\lambda)$ represents surface albedo and is one of the input data necessary for calculations whereas atmosphere albedo could be expressed as:

$$
r_{s}(\lambda)=T_{O 3}^{\prime}(\lambda) T_{w v}^{\prime}(\lambda) T_{a a}^{\prime}(\lambda)\left\{0.5\left[1-T_{r}^{\prime}(\lambda)\right]+\left(1-F^{\prime}\right) T_{r}^{\prime}(\lambda)\left[1-T_{a s}^{\prime}(\lambda)\right]\right\}
$$

In the relation (13) $F$ denotes the contribution of radiation scattered towards the lower hemisphere, which in the case of molecular scattering could be accepted as 0.5 and for aerosol attenuation depends on the solar zenith angle:

$$
\begin{gathered}
F=1-0.5 \cdot \exp [(A F S+B F S \cdot \cos \vartheta) \cdot \cos \vartheta] \\
A F S=A L G \cdot[1.459+A L G \cdot(0.1595+A L G \cdot 0.4129)] \\
B F S=A L G \cdot[0.0783+A L G \cdot(-0.3824-A L G \cdot 0.5874)] \\
A L G=\ln (1-<\cos \theta>)
\end{gathered}
$$

Asymmetry factor $<\cos \theta>$ was accepted for so called rural atmosphere model (0.65). In relation (18) the parameters with apostrophe were calculated applying $M=1.8$, and in the formula defining $F-\cos \vartheta=\frac{1}{1.8}$. Finally, the obtained expression for $E_{d}(\lambda)$ is multiplied by $C$ coefficient: 


$$
C=\left\{\begin{array}{cc}
(\lambda+0.55)^{0.8} & \text { for } \lambda \leq 0.45 \mu \mathrm{m} \\
1.0 & \text { for } \lambda>0.45 \mu \mathrm{m}
\end{array}\right.
$$

Reassuming, the determination of the illumination or radiation dose at the sea level by means of the presented algorithms requires the knowledge only on two parameters of atmospheric conditions, the atmospheric pressure and the water vapour pressure, routinely registered at the sea level at meteorological stations. Albedo of the sea area was accepted as constant and equal to 0.06 .

\subsection{Cloudiness}

Traditionally, clouds have been observed visually by trained technicians at weather stations and onboard ships around the world (often in units of eighths, or oktas), following the general rules outlined by the World Meteorological Organization (WMO, 1975). Before "the satellite epoch" the influence of cloudiness on the solar irradiation at the Earth's surface has been taken into account by using these visual observations of the cloud cover as input data in the simple models. The longer the averaging time was the better coherence of measured and calculated results was obtained. Apart from the subjectivity of such observations, their number as well as time and spatial resolution over the seas and oceans, make these results unreliable. Accounting for high temporal variability of cloudiness, meteorological models as a source of the input data are also a source of serious errors (Krężel \& Kozłowski, 2001). Nevertheless, if the cloudiness over the area of interest is known the average energy flux at the horizontal plane can be expressed as:

$$
E=E_{0} T_{C l}
$$

where: $E_{0}$ - irradiance reaching the sea surface in the case of cloudless atmosphere; $T_{C l}$ - a

function describing the influence of an average cloudiness on the light transmission, given by Krężel (1985):

$$
T_{C l}=1-a_{C l} c-b_{C l} c^{2}
$$

where: $c$ - cloudiness in tenth, $a_{C l}$ i $b_{C l}$ - best-fit coefficients.

Assuming the independence of $T_{C l}$ on the wavelength the formulas (24) and (25) complement the model with this very important component and make it applicable for the atmosphere.

\section{Satellite sources of input data}

\subsection{Aerosol optical thickness}

In the next approximation, it is assumed to utilise the Advanced Very High Resolution Radiometer (AVHRR) data. The upward radiance over the dark sea surface within red and infrared bands depends primarily on the type and concentration of aerosols in the atmosphere. The amount of solar radiation backscattered by aerosols is proportional to the aerosol optical thickness $\tau_{a}$ and the phase function $P^{A}(\gamma)$. Light attenuation by marine aerosols arises mainly from the scattering processes (i.e. the single scattering albedo $\omega^{\prime}=1$ ). Therefore, the 
dependence between the radiance measured by the space-borne radiometer and $\tau_{a}$ should also allow for the light source-observation direction geometric configuration. This means that $P^{A}(\gamma)$ has to be known in order to determine the value of $\tau_{a}$ (Stowe et al., 1997).

Results of hitherto investigations indicated that the variability of $P^{A}(\gamma)$ in the case of backscattering is considerably lower than the $\tau_{a}$ variability, and even, to a certain extent, does not depend on the type of aerosols (Stowe et al., 1997). Koepke \& Quenzel (1979) showed that the variability of $P^{A}(\gamma)$ is contained within the range of about $\pm 25 \%$ (and can be lowered down to $\pm 4 \%$ in the case of optimal geometric configuration), whereas $\tau_{a}$ can range even over an order of magnitude. The feasibility of $\tau_{a}$ determination based on a single spectral channel data on reflectance was proved by Kaufman (1993) who stated the universality in the dependence between $\tau_{a}$ and the path radiance.

Standard algorithms used to determine the aerosol optical thickness on the basis of data from a single spectral channel (1 or 2) of the AVHRR, which were developed for NOAA/NESDIS4 (first-generation algorithm), allow for the geometric configuration of the system. Moreover, the correction referring to the actual distance between the Earth and the Sun is considered, and the values are rescaled according to the wavelength of $0.5 \mu \mathrm{m}$ (rescale coefficient is 1.348). Additional parameters used as the input data are i) the ocean albedo (Lambert's reflection coefficient), ii) volumetric absorption and scattering coefficients and iii) the phase function $P^{A}(\gamma)$ which is determined on the basis of the Mie theory and redefined for the model of aerosol particles.

The values of $A O T(500 \mathrm{~nm})$ calculated by means of the above-mentioned algorithm are rendered accessible in a quasi-operational mode by NOAA/NESDIS. Utilisation of AVHRR data in AOT determination enables gaining information on the values of this parameter within a spectral interval of $100 \mathrm{~nm}$ with the central value at $630 \mathrm{~nm}$. The algorithm enabling one to determine the AOT variability within the whole visible spectrum was developed basing on the analysis of measurement data recorded mainly on Gotland, within the framework of AERONET ${ }^{5}$ program. Functional dependencies enabling determination of AOT for optional wavelength within PAR band were obtained (Krężel et al., 2008):

$$
A O T(\lambda)=A O T(500) a \exp b(\lambda)
$$

where: AOT(500) - the aerosol optical thickness at $500 \mathrm{~nm}$ determined on the basis of AVHRR data by means of the first-generation algorithm, $a$ - empirical coefficient equal to $1.63, \lambda$ - the wavelength [nm], $b(\lambda)$ - coefficient related to the wavelength $\lambda$, which can be described by the following formula:

$$
b(\lambda)=4.588 \exp (-2.981 \lambda / 1000)
$$

Dependencies (26) - (27) make it possible to obtain digital images of $\tau_{a}(\lambda)$, which are presented in Fig. 3.

\footnotetext{
${ }_{4}^{4}$ National Oceanic and Atmospheric Administration /National Environmental Satellite, Data, and Information Service

${ }^{5}$ Aerosol Robotic Network - http:/ / aeronet.gsfc.nasa.gov/
} 

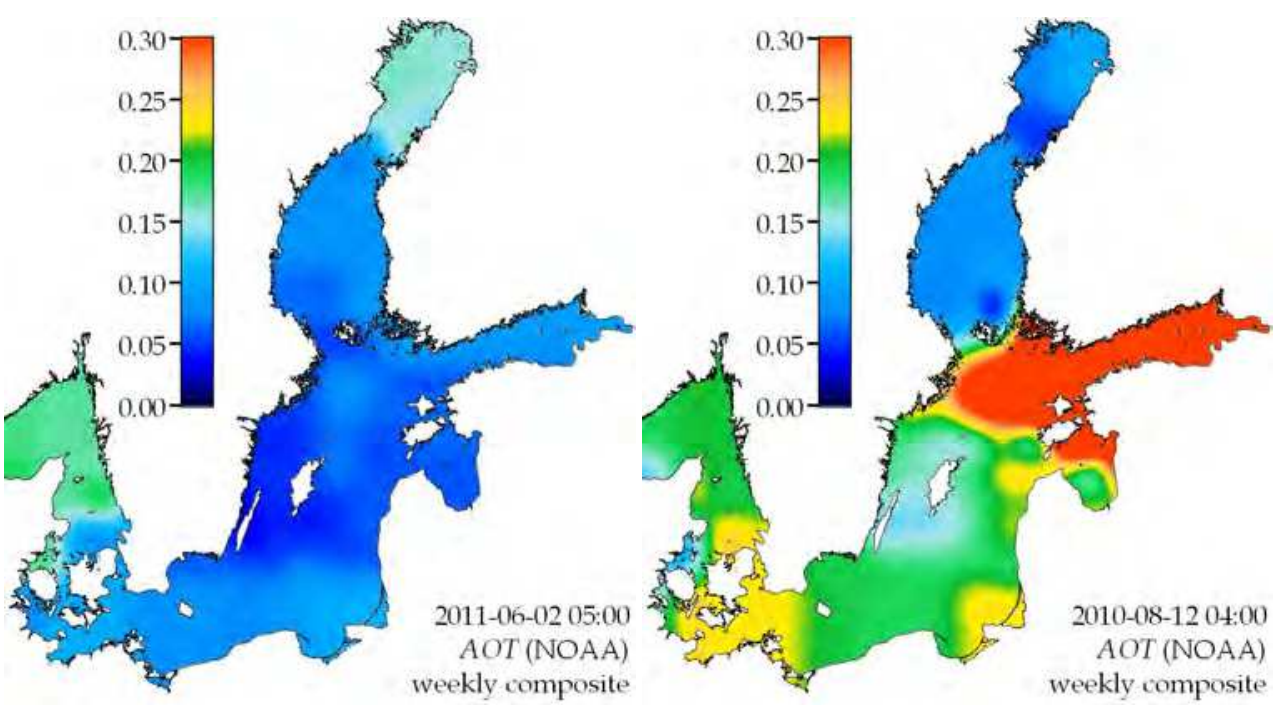

Fig. 3. Exemplary maps of aerosol optical thickness over the Baltic Sea calculated on the basis of interpolated AVHRR channel 1 data

\subsection{Water vapour}

The water vapour is present in the troposphere - the lower part of the atmosphere. Its content varies significantly with space and time, being dependent on the air temperature. At the sea level, concentration of water vapour can change from $10^{-2} \mathrm{gm}^{-3}$ at high latitudes up to $30 \mathrm{gm}^{-3}$ in the equatorial regions. It is one of the most important atmosphere constituents that attenuates radiation. The strongest absorption occurs far out in the infrared part of the solar spectrum, making atmosphere almost opaque for the wavelengths in the range of about 30-900 $\mu \mathrm{m}$. Weaker water vapour absorption bands affect transmittance windows that are useful for remote sensing in the near infrared (NIR), thermal-infrared (IR) and microwave (MW). It provides a way to retrieve water vapour content on the basis of satellite measurements of reflected solar NIR radiation or emitted by the Earth's surface IR and MW radiation.

The humidity of the atmosphere can be expressed in different ways, e.g. absolute humidity, specific humidity, dew point temperature or integrated precipitable water vapour (IPWV). In the satellite techniques the latter one, also called the integrated column water vapour or total atmospheric water vapour (denoted $W$ ), is used. It expresses the height of the layer of liquid water, obtained by condensing all the water vapour in the zenith direction at the surface of a unit area. A layer of $1 \mathrm{~cm}$ thickness corresponds to $1 \mathrm{~g}$ of precipitable water per $1 \mathrm{~cm}^{2}$ of the area.

In the NIR part of the spectrum, the absorption peaks of the water vapour are located mainly around 720, 820 and $940 \mathrm{~nm}$. The differential absorption technique utilizing this region of spectrum assumes, in general, that the integrated water vapour content is related to the transmission in a spectral channel affected by the water vapour absorption and that the transmission can be estimated using the radiance ratio of two bands - absorption and 
non-absorption ones. It comes from the simplification of the Lambert's law (Gao \& Goetz, 1990; Bouffiès et al., 1997; Tahl \& von Schoenermark, 1998). As the assumptions undergoing the theory cannot be true in reality, nonlinear relationships are used in practice. The disadvantage of this method is limitation to daytime measurements and its high sensitivity to aerosols and thin clouds - their occurrence can lead both to overestimation (photon path enlarged due to multiple scattering) or underestimation (photon path reduced due to backscattering) of the atmospheric humidity content.

In the recent years, studies in retrieving total atmospheric water vapour content based on the absorption technique has been carried out using sensors such as the Medium Resolution Imaging Spectrometer (MERIS) working onboard the European Envisat satellite (Fischer \& Bennartz, 1997) and Moderate Resolution Imaging Spectrometer (MODIS) onboard two U.S. American platforms, Terra and Aqua (Gao \& Kaufman, 2003; Albert et al., 2005; Moradizadeh et al., 2008). The general form of the water vapour retrieval algorithm for MERIS level 2 products is (ESA, 2006):

$$
W=k_{0}+k_{1} \log \left(\frac{L_{C h 15}}{L_{C h 14}}\right)+k_{2} \log ^{2}\left(\frac{L_{C h 15}}{L_{C h 14}}\right)^{2}
$$

where $L_{C h 14}$ and $L_{C h 15}$ are the radiances measured in MERIS channels 14 and 15 respectively, and $k_{0}, k_{1}$ and $k_{2}$ are the regression coefficients, dependent on few factors, with the geometry of observation among them. The absorption band 15 is centred at $900 \mathrm{~nm}$ and the reference non-absorption band 14 at $885 \mathrm{~nm}$. Above land surfaces, top of the atmosphere (TOA) radiances are corrected for the spectral slope of the surface albedo prior to applying the algorithm. Above water surfaces, the algorithm additionally takes into account the aerosol optical thickness, except for regions where the Sun glint is significant. Correction is made using AOT at $900 \mathrm{~nm}$ estimation based on the radiances measured at MERIS bands 12 (775 $\mathrm{nm})$ and $13(865 \mathrm{~nm})$. The advantage of the second instrument, MODIS, is that it has two more channels in the infrared spectral region, where the water vapour absorption occurs. Thus, the water vapour content is calculated as the weighted mean of three independent estimations (NASA MOD05 algorithm) performed according to (Gao \& Kaufman, 1998, 2003):

$$
W_{i}=a_{0}+a_{1}\left(\frac{L_{C h i}}{L_{C h 2}}\right)+a_{2}\left(\frac{L_{C h i}}{L_{C h 2}}\right)^{2}
$$

where $L_{C h i}$ are the radiances measured in MODIS water vapour absorption channels 17,18 or 19, centred around 905, 936 and $940 \mathrm{~nm}$ respectively. Non-absorption reference band 2 has its centre at $865 \mathrm{~nm}$. It have to be mentioned that these three bands have different water vapour sensitivity (Sobrino \& El Kharraz, 2003), so weighting factors for averaging are calculated based on the range of possible water vapour content and the transmissivities in band $i$.

Global data of both sensors are available with the nadir resolution of $1 \mathrm{~km}$. MERIS full resolution of $300 \mathrm{~m}$ can be used locally for more detailed water vapour estimation (Fig. 4). Near polar orbits and wide swath of these systems enable to observe each point at the Earth's surface at least once every two days. Higher temporal resolution can be provided 
using sensors measuring emitted infrared radiation, such as AVHRR or the Spinning Enhanced Visible and Infrared Imager (SEVIRI). The AVHRR, which is carried by the American TIROS-N/NOAA series of satellites since 1979, provides long time series of data with about $1 \mathrm{~km}$ spatial resolution. NOAA satellites, working in pairs, can give information on the same point of the surface at least 4 times per day. SEVIRI, operating on board of meteorological geostationary satellites provides data with coarser spatial resolution depending on distance from the sub satellite point (about $3.3 \mathrm{~km}$ at the central Baltic Sea) but with very high temporal resolution - up to $15 \mathrm{~min}$ from the recently working Meteosat Second Generation satellite (MSG).
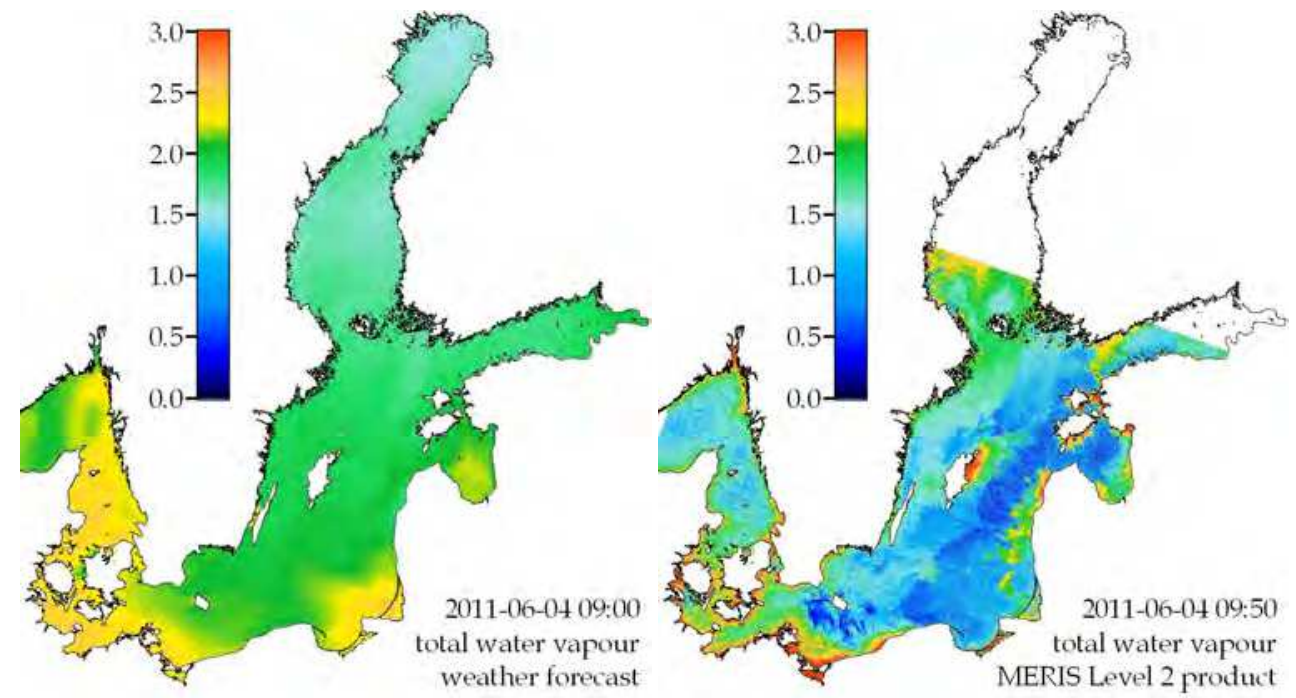

Fig. 4. Exemplary maps of total atmospheric water vapour over the Baltic Sea region calculated on the basis of a weather prediction model (left) and a standard MERIS Level 2 product under clear sky conditions (right) for the same day

Both instruments have two spectral bands in the range of 8.5-12.5 $\mu \mathrm{m}$ atmospheric window, which is affected by the water vapour absorption. These are AVHRR's band 4 (10.3-11.3 $\mu \mathrm{m})$ and $5(11.5-12.5 \mu \mathrm{m})$ or SEVIRI's band $9(9.8-11.8 \mu \mathrm{m})$ and $10(11.0-13.0 \mu \mathrm{m})$. Using measurements of radiation at two wavelengths in retrieving the surface brightness temperature makes it possible to limit the influence of the atmosphere brightness temperature on the calculated values of the water vapour content. This is a so-called splitwindow technique, that can be used directly to obtain the surface brightness temperature and, if an independent estimate of the mean brightness temperature of the atmosphere is available, also the column-integrated water vapour.

In practice the split-window technique is rarely used directly to obtain water vapour from sensors measuring emitted infrared radiation. Several simplified methods utilising regression have been proposed instead of it. To retrieve humidity content from the AVHRR and SEVIRI thermal channels a method based on the linear atmosphere-surface temperature relationship (LASTR) can be used (Sobrino et al., 2002; Sobrino \& Romaguera, 2008). It 
considers a simple linear relationship between $W$ and the atmospheric transmittance $(\tau)$ in channel 4 of AVHRR or 9 of SEVIRI. Best fit regression coefficients for each instrument was derived based on simulations of atmospheric models. In the case of SEVIRI they are a function of the viewing geometry by means of the cosine of satellite zenith angle. The transmittance through the atmosphere from the surface to the satellite in channel $i$, for a cloud-free situation, and considering the emissivity as being equal to one for a blackbody, can be obtained from the radiative transfer equation as:

$$
\tau_{i}=\frac{T_{i}-T_{a i}}{S S T-T_{a i}}
$$

where $T_{i}$ is the brightness temperature retrieved from the radiance measured in channel $i, T_{a i}$ is the effective atmospheric temperature (resulting from the whole column of the atmosphere) and SST is the sea surface temperature. SST can be derived from the same data using the split-window algorithm. Its nonlinear form NLSST is recommended (Walton et al., 1998). The effective atmospheric temperature is strongly correlated with SST values thus can be obtained with sufficient accuracy using linear regression.

The new SEVIRI instrument has two more water vapour channels at 6.2 and $7.3 \mu \mathrm{m}$, that improves possibilities of water vapour retrieval. However, IR radiometry has the same limitation as mentioned before - it allows to estimate the humidity content only under clear sky conditions. In the presence of clouds, only the microwave techniques can be used. Similar methods, accounting for measurements at two frequencies $(22.235$ and $31 \mathrm{GHz})$ has been developed. They can be used to retrieve precipitable water over the ocean (but not over the land) based on observations provided for example by the Special Sensor Microwave/Imager (SSM/I) and its successor (SSMIS) onboard a series of platforms in the US Defence Meteorological Satellite Programme (DMSP) or the Advanced Microwave Scanning Radiometer (AMSR-E) onboard NASA's Aqua satellite. The advantage of 'seeing through clouds', however, is reduced by coarse ground resolution, that cannot be finer than $25 \mathrm{~km}$.

\subsection{Ozone}

The amount of the total stratospheric ozone has been regularly measured since the mid 1950s. It is usually expressed in Dobson units (DU). 100 DU correspond to the amount of ozone that would produce a layer of $1 \mathrm{~mm}$ of thickness at pressure of $1 \mathrm{~atm}$. The highest concentrations of ozone in the stratosphere occur at about $25 \mathrm{~km}$ at the equator and $20 \mathrm{~km}$ in the northern polar regions. The average values are about $300 \mathrm{DU}$ but they vary significantly in space and over the year.

Ozone has absorption lines in all major portions of the electromagnetic spectrum so it can be measured with a variety of techniques. The most important for the satellite measurements of integrated ozone are the ultraviolet Huggins bands $(310-350 \mathrm{~nm})$ and Chappuis bands in the visible part of the spectrum $(380-750 \mathrm{~nm})$, where absorption occurs due to dissociation of ozone. There is also an infrared ozone absorption band at $9.6 \mu \mathrm{m}$ connected with changes in the vibrational state of the molecules.

Satellite remote sensing of the total ozone in both the stratosphere and troposphere is based mainly on measurements of the ultraviolet albedo of the Earth. Instruments which currently 
measure these albedos are the Solar Backscatter Ultraviolet Spectrometer (SBUV/2) and the Global Ozone Monitoring Experiment (GOME-2) onboard NOAA and METOP 2 satellites. Previous GOME instrument operated from the ESA platforms as well. Both instruments are nadir-looking sensors, thus ozone maps are generated using interpolation and smoothing procedures.

Algorithms to retrieve the total ozone utilize the split-window technique using measurements of radiation in two closely spaced channels in the Hartley-Huggins bands. Channels 2 and 3 of GOME fulfil these requirements. They are characterised by limited interference from other trace gas absorbers and a smaller interference of Ring effect (partially filled Fraunhofer lines in the backscattered spectrum). SBUV/2 measures backscattered radiance at 12 discrete wavelengths in the range of spectrum between 252 and $340 \mathrm{~nm}$, giving possibility to retrieve vertical profiles of the ozone concentration (Bhartia et al., 1996).

The infrared ozone absorption band is utilized by TIROS-N Operational Vertical Sounder (TOVS) processing the data recorded by High Resolution InfraRed Sounder (HIRS/2). The ozone retrieval regression algorithm uses channels $9(9.71 \mu \mathrm{m}), 8(11.11 \mu \mathrm{m})$, and $3(14.49$ $\mu \mathrm{m})$ (Engelen \& Stephens, 1997). Channels 3 and 8 are incorporated in order to correct the ozone-sensitive channel 9 for the temperature dependence. Climatological data are used to incorporate the unobserved upper layer of the atmosphere (Neuendorffer, 1996). The $9.7 \mu \mathrm{m}$ IR channel is also present in the SEVIRI. This channel measures ozone concentration at high temporal and spatial resolution, in near-real-time mode. The algorithm uses an optimal estimation approach to fit the calculated 9.7 channel radiances to the observed values by adjusting the ozone quantity in the $1000-30 \mathrm{hPa}$ layer with constraining boundary conditions from the European Centre for Medium-Range Weather Forecasts (ECMWF) and the $10.8 \mu \mathrm{m}$ channel observations (EUMETSAT, 2010).

Reanalised SBUV/2 and TOVS ozone products are provided in form of global ozone grids with spatial resolution of $1^{\circ}$ and temporal resolution of 1 day by TOAST System 6 . GOME-2 products can be obtained from NESDIS with the same temporal resolution but at $1^{\circ} \times 1.25^{\circ}$ spatial grids. Our solar irradiance model does not utilize the satellite ozone data yet.

\subsection{Cloudiness}

It is out of discussion that pretty-nearly any space born information on cloudiness, especially over the seas and oceans, is better than that calculated even by advanced meteorological models (Fig. 5). Nevertheless, because of the complicated structure of clouds in the terrestrial atmosphere, variability in their consistency, diversification of water drops size and ice particles' shape etc. there is no easy way to presume the optical thickness of clouds basing on the analysis of the solar radiance reflected from their surface and recorded by a satellite-borne radiometer. For instance the problem of the cloudiness influence on the solar energy flux reaching the sea surface can be divided into two stages:

- it has to be determined whether the Sun was obstructed by clouds at a given point and time or not - wrong answer to this question leads to over- or underestimation of considered parameter value almost by an order of magnitude,

\footnotetext{
${ }^{6}$ Total Ozone Analysis using SBUV/2 and TOVS
} 
- if the Sun is obstructed by clouds, it has to be determined which and to what degree the properties of clouds influence the value of considered parameter - correct solution to this problem improves the accuracy of estimation by several percent.
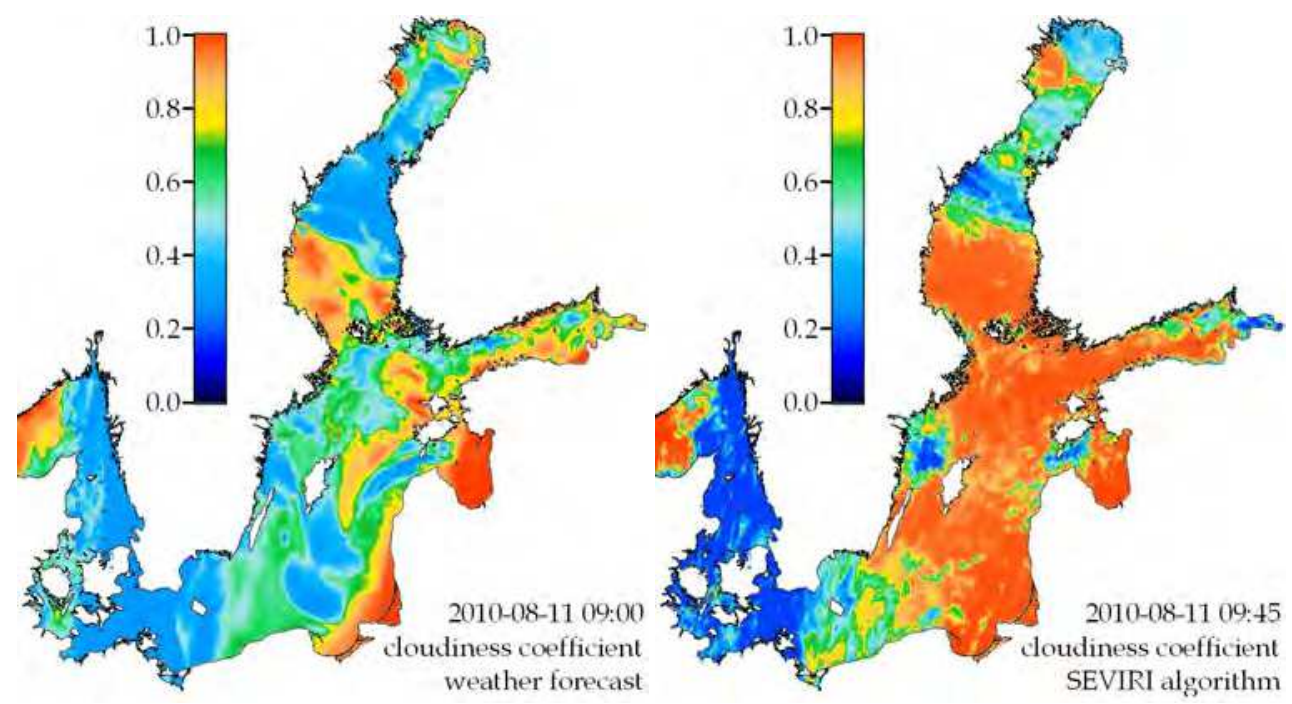

Fig. 5. Exemplary maps of the cloudiness coefficient over the Baltic Sea region calculated on the basis of a weather prediction model and SEVIRI observation for the same day

Previous studies (see e.g. Krężel, 1985) showed that if i) the differences arising from astronomical reasons are filtered, ii) the areas with direct reflection of the solar radiation are omitted and iii) the period of time or places where the sea is covered with ice are not taken into consideration, then the most important factors significantly affecting the radiance reaching a satellite-born sensor are the degree of the sky cloud cover over the area from which the signal recorded by a satellite is generated and the optical thickness of clouds obstructing the sun rays. The basic problem to solve in this case is to determine the threshold values, i.e. to determine the values of albedo under cloudless sky and total cloud cover conditions and to decide how to analyse the in-between cases. The difficulty arises from the fact that the threshold value is a function of many variables, i.e. the surface type (land, sea and their variability), its physical properties (e.g. temperature, humidity, concentration of some substances in the water etc.), current weather conditions (e.g. wind, fog) and the Sun-pixel-satellite geometric configuration. It means that in the case of the water surface the problem is a little bit lighter. Maybe the simplest method to solve it is to adopt formulas (24) and (25) by introducing another variable in the place of $c$. It has been suggested (Krężel et al., 2008) to introduce a cloudiness coefficient $c_{T}$, a function of albedo determined on the basis of the analysis of Meteosat visible channel data, into formula (25). Within the area of the sea, the albedo is the lowest where the sky is cloudless and the highest where a thick layer of clouds covers a whole pixel. In-between values depend mainly on the degree of cloud and/or fog cover of each pixel and, on a smaller scale, on the transmittance of clouds and fog. Theoretically, the value of albedo determined from a satellite contains resultant information, i.e. the value of albedo is almost the same in the case 
of a pixel covered in 50\% with a thick layer of opaque clouds and a pixel totally covered with clouds characterized by transmittance of $50 \%$. In the former situation the cloudiness $c=$ 0.5 and the cloudiness coefficient $c_{T}=0.5$, whereas in the later case $c=1$ and $c_{T}=0.5$.

Replacing $c$ in formulas (24) and (25) with $c_{T}$ should result in significant improvement of obtained results. Nevertheless, the differences between calculated and measured instantaneous irradiance (especially in the case of extreme values) can be still expected, because the coefficient $c_{T}$ does not contain information on such phenomena as light reflection from side edges of the clouds of cumulus type, or the thickness of the cloud layer, because when the thickness exceeds a certain value its further increase does not affect the satellite-measured albedo. The decrease in averaging period will result in higher differences between modelled and measured values. Of course, on account of introduction of a new variable, new values of regression coefficients in equation (25) should be determined.

\section{Conclusion}

We calculated the downwelling PAR irradiance over the Baltic Sea applying the model with the use of two sources of input data: no-satellite and satellite in order to evaluate the influence of application of the information on the atmosphere constituents obtained by means of remote sensing technique on the accuracy of the light transmission model retrievals. The sources of the non-satellite data on cloudiness and total atmospheric water vapour (retrieved from modelled dew point temperature) were numerical weather predictions provided by ICM7 UM model (spatial resolution $4 \mathrm{~km}$, four 48 -h forecasts per day with temporal resolution of $1 \mathrm{~h}$ ). In the case of the AOT the average climatological values were applied (Krężel, 1985). As the satellite sources, SEVIRI and AVHRR observations were used together with calculations described in previous sections to provide the cloudiness coefficient and AOT. Water vapour content was taken from the standard Level 2 products of MERIS (only for clear sky conditions). Ozone concentration was assumed as constant, averaged over the whole region (Table 1). The results of calculations were validated on the basis of the values of the downward irradiance recorded at the Institute of Oceanography's automatic measurement station in Hel in the period since August 2010 to May 2011. The comparison was made using a reference pixel whose central point was located about $7 \mathrm{~km}$ north-east of the station (Fig. 6).

The values of PAR irradiance modelled on the basis of non-satellite data appear to be in good agreement with measurements, which is confirmed by high correlation coefficient (Fig. 7). It proves the correctness of used formulae and the quality of model calibration. However, the cloud of points on the scatterplot, pointing both overestimation and underestimation of irradiance by modelled data, indicate that for individual cases the differences may be even more than $100 \%$. The irradiance time series show it more clearly (Fig. 8). Deviations of modelled values from measured ones lay within the range of $-265 \div 210 \mathrm{Wm}^{-2}$. Using satellite data improves results of the modelling even in case of applying only the satellite evaluation of cloudiness (Fig. 7, Table 2). It reduces the statistical error by over $10 \mathrm{Wm}^{-2}$. It proves that the most important factor affecting the irradiance, the cloudiness coefficient,

\footnotetext{
7 ICM - Interdisciplinary Centre for Mathematical and Computational Modelling, University of Warsaw, Poland (http:/ /www.icm.edu.pl)
} 
should be determined with better accuracy than that of a weather prediction model. High temporal resolution of SEVIRI observations enabled to reproduce diurnal fluctuations in the illumination under variable clouds condition with better accuracy (Fig. 8).

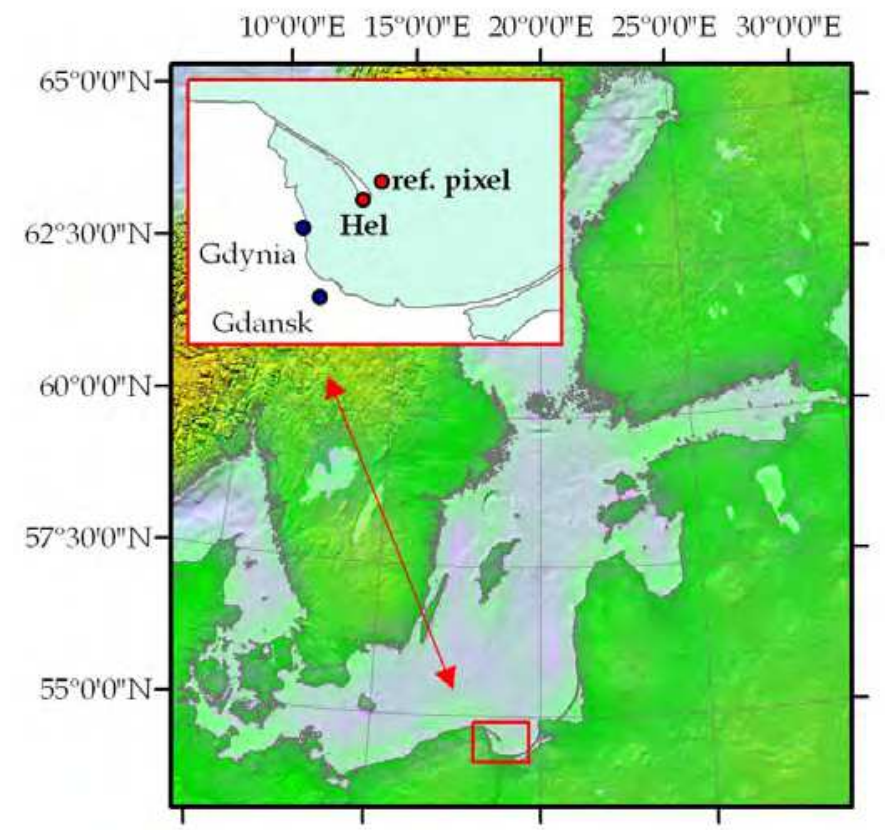

Fig. 6. Area of investigation
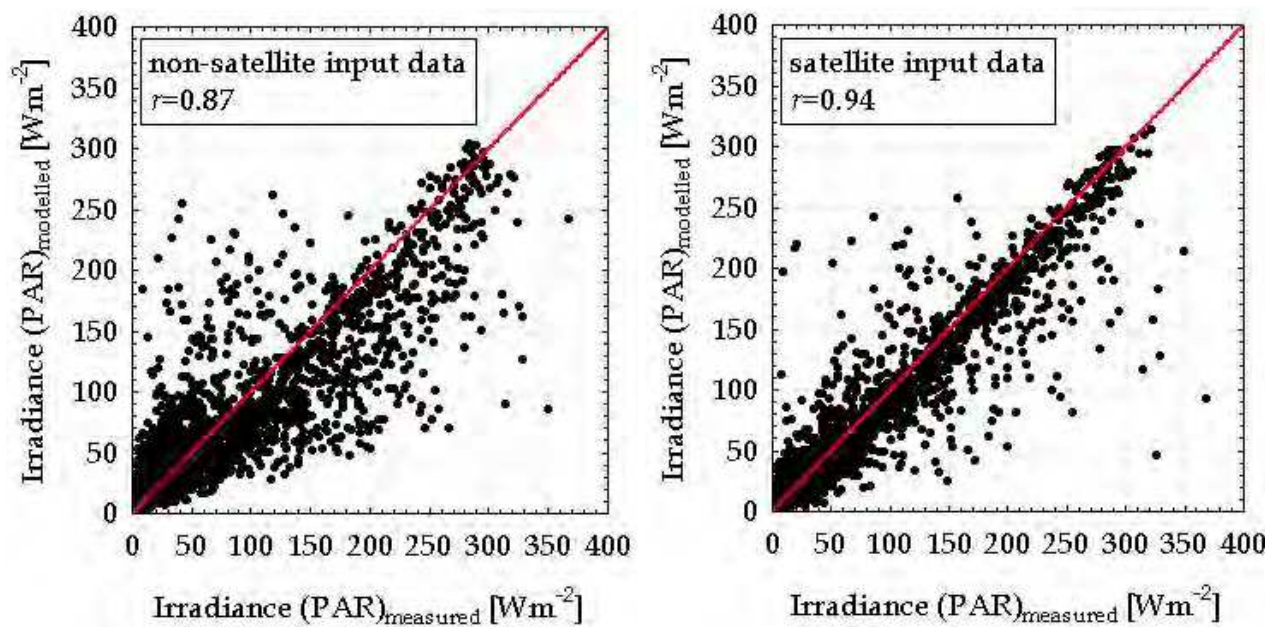

Fig. 7. Values of PAR irradiance at Hel - observed and modeled with two sets of input data for the period of 2010-08-26 to 2011-05-24 ( $r$ - linear correlation coefficient between modelled and measured data) 


\begin{tabular}{|c|c|c|c|c|c|c|c|}
\hline \multicolumn{4}{|c|}{ input data source } & \multicolumn{5}{|c|}{ statistics } \\
\hline$c$ & $A O T$ & $W$ & $n$ & $\min$ & $\max$ & mean & st.dev. \\
\hline $\mathrm{ns}$ & $\mathrm{ns}$ & $\mathrm{ns}$ & 2535 & -264.8 & 211.0 & -8.07 & 38.68 \\
\hline $\mathrm{s}$ & $\mathrm{ns}$ & $\mathrm{ns}$ & 2535 & -282.1 & 185.1 & -10.00 & 26.94 \\
\hline $\mathrm{s}$ & $\mathrm{s}$ & $\mathrm{ns}$ & 2535 & -281.2 & 196.5 & -4.79 & 26.89 \\
\hline $\mathrm{s}$ & $\mathrm{s}$ & $\mathrm{s}$ & 2535 & -281.2 & 196.9 & -4.75 & 26.90 \\
\hline
\end{tabular}

Table 2. Statistical characteristics of modeled PAR irradiance values deviation from measured ones $\left[\mathrm{Wm}^{-2}\right]$ ( $n$ - number of data, st.dev. - standard deviation) for different input data sets (satellite - s; non-satellite - ns) of cloudiness coefficient $(c)$, aerosol optical thickness $(A O T)$ and total atmospheric water vapour $(W)$
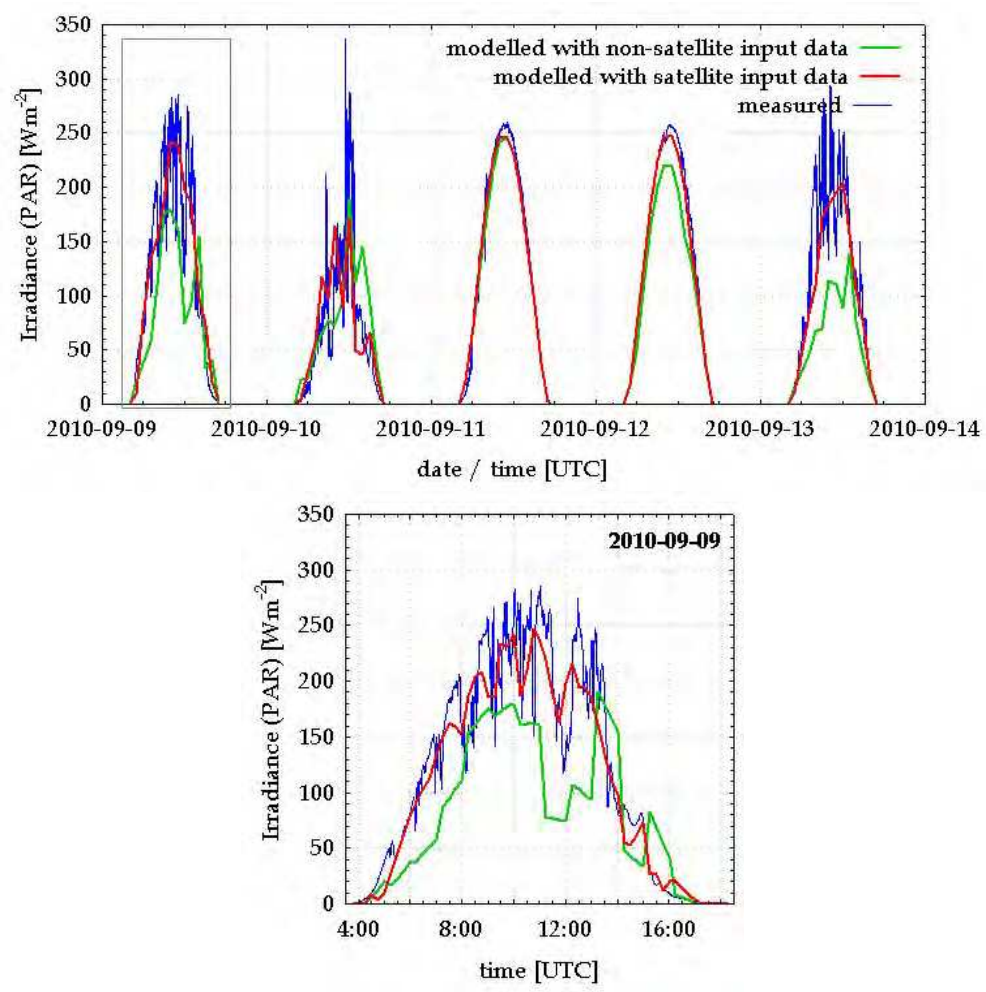

Fig. 8. Values of PAR irradiance at Hel - observed and modelled with two sets of input data for 5 day time series (temporal resolution of calculations $1 \mathrm{~h}$ ) and 1 day time series (temporal resolution of calculations $15 \mathrm{~min}$.)

Accounting for the satellite AOT data instead of climatological values makes further decrease in errors reducing the systematic underestimation of modelled data (Table 2). The water vapour influences the whole PAR irradiance in a less degree. More realistic spatial distribution of evaluated PAR irradiance seems to be the most valuable improvement of 
modelling provided by the satellite input data set. As it results from the presented examples (Fig. 9), applying the satellite data in the solar radiation transmission models significantly reduces the calculation errors. Consequently, it can influence the evaluation of other processes and phenomena occurring in the sea or estimations of the energy budget etc. Considering the fact that most of the satellite data are now available for operational use, their utilisation should become common.
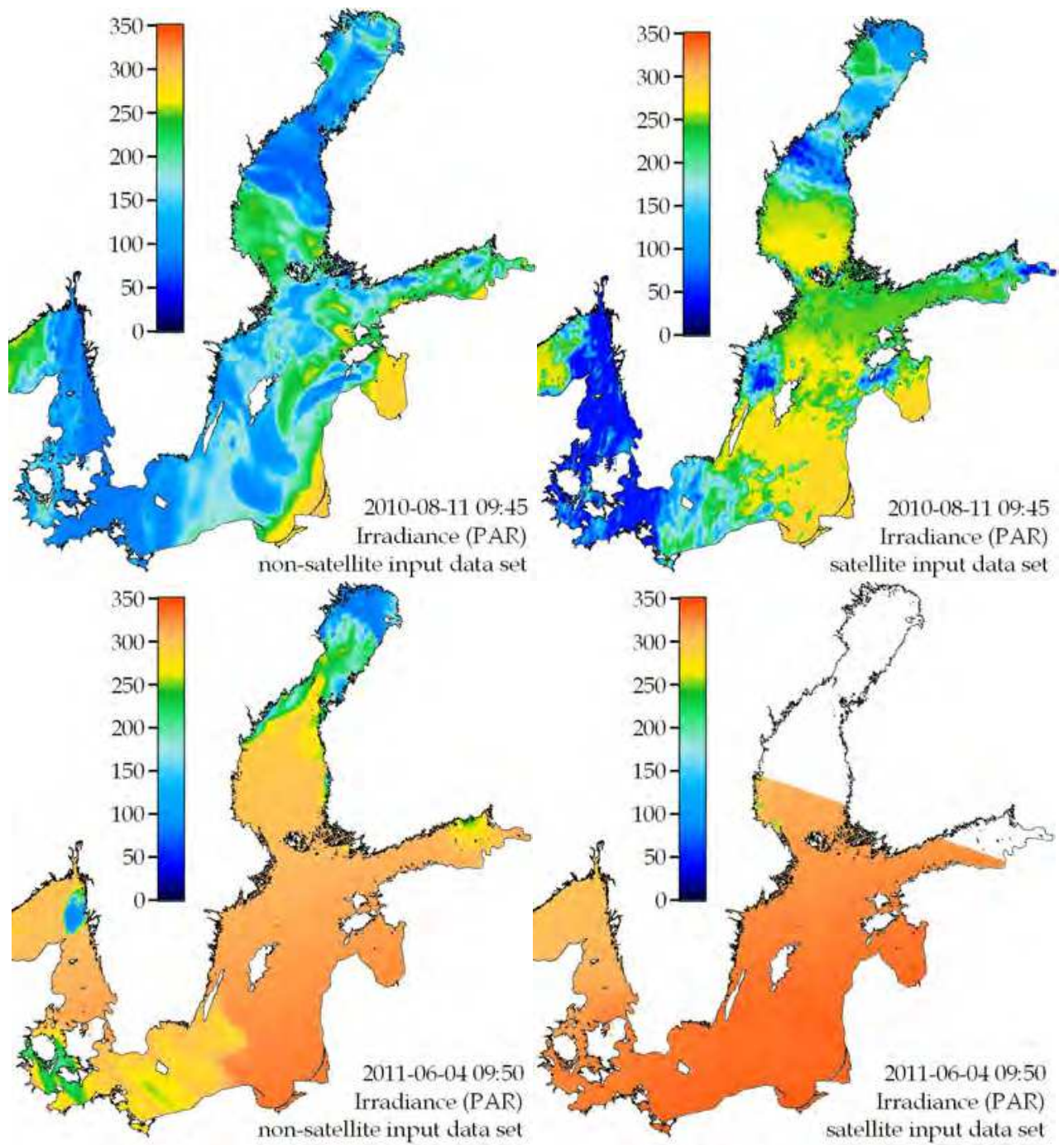

Fig. 9. Exemplary maps of PAR irradiance at the Baltic Sea surface modelled on the basis of two input data sets (non-satellite or satellite) under cloudy (2010-08-11) and clear-sky (201106-04) conditions 
It is worth noticing that clouds are the most important atmosphere constituent which influences the accuracy of calculations of the solar energy flux at the sea surface. On the other hand, due to radiometers working onboard geostationary satellites, nowadays the cloudiness can be determined, in operational mode, with temporal resolution of 15 minutes. The scale of the temporal and spatial variability is shown in Fig. 10. Consequently, there is an opportunity to monitor the short-term variability in the sea surface layer resulting from the changes in the intensity of the solar radiation, e.g. water mixing, phytoplankton blooms, primary production rate.

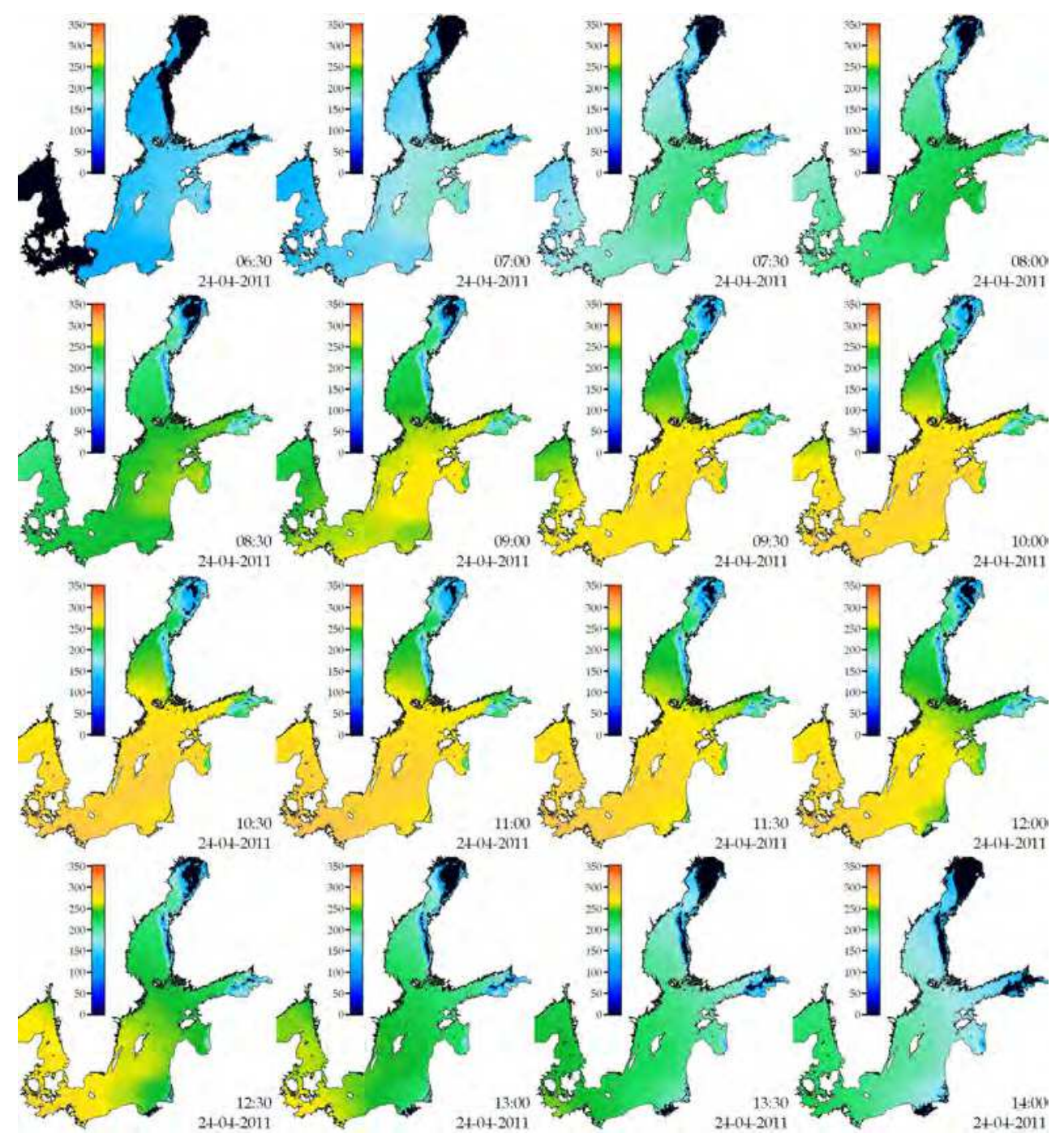

Fig. 10. Exemplary time series of PAR irradiance at the Baltic Sea surface modelled using the satellite (SEVIRI) data 


\section{References}

Albert P., Bennartz R., Preusker R., Leinweber R., Fischer J. (2005). Remote Sensing of Atmospheric Water Vapor Using the Moderate Resolution Imaging Spectroradiometer, Journal of Atmospheric and Oceanic Technology, 22, 309-314.

Angström A. (1963). The parameters of atmospheric turbidity, Tellus, 16, 64-75.

Bhartia P.K., McPeters R.D., Mateer C.L., Flynn L.E., Wellemeyer C.G. 1996. Algorithm for the estimation of vertical profiles from the backscattered ultraviolet technique, $J$. Geophys. Res., 101, 18793-18806.

Bird R.E., Riordan C. (1986). Simple solar spectral model for direct and diffuse irradiance on horizontal and tilted planes at the Earth's surface for cloudless atmospheres, J. Clim. Appl. Meteor., 25, 1, 87-97.

Bouffiès S., Bréon F. M., Taneé D., Dubuisson P. (1997). Atmospheric water vapor estimate by a differential absorption technique with the Polarization and Directionality of the Earth Reflectances (POLDER) instrument, J. Geophys. Res., 102 (D3), 3831-3841.

Dera J., Woźniak B. (2010). Solar radiation in the Baltic Sea, Oceanologia, 52(4), 533-582.

Engelen R.J., Stephens G.L. 1997. Infrared radiative transfer in the $9.6 \mu \mathrm{m}$ band: Application to TIROS operational vertical sounder ozone retrieval, J. Geophys. Res., 102, D6, 6929-6939.

EUMETSAT. (2010). Total Ozone - Factsheet, EUM.OPS.DOC.09.5179, http:/ / www.eumetsat.int/idcplg?IdcService=GET_FILE\&dDocName=PDF_TOZ_ FACTSHEET\&RevisionSelectionMethod=LatestReleased.

ESA. (2006). MERIS Product Handbook, 130 pp. http://envisat.esa.int/pub/ESA_DOC/ENVISAT/MERIS/meris.ProductHandboo k.2_1.pdf.

Fischer J., Bennartz R. (1997). Retrieval of total water vapour content from MERIS measurements, Algorithm Theoretical Basis Document ATBD 2.4, Doc. PO-TN-MELGS-0005, 19 pp.

Gao B.-C., Goetz A. F. H. (1990). Column atmospheric water vapor and vegetation liquid water retrievals from airborne imaging spectrometer data, J. Geophys. Res., 95, 3549-3564.

Gao B.-C., Kaufman J. (1998). The MODIS near-IR water vapour algorithm, Algorithm Technical Background, Doc. ATBDMOD-03, 25 pp.

Gao B.-C., Kaufman J. (2003). Water vapor retrievals using Moderate Resolution Imaging Spectroradiometer (MODIS) near infrared channels, J. Geophys. Res., 108, 4389, doi:10.1029/2002JD003023.

GCOS-GAW Agreement Establishing the WMO/GAW Global Atmospheric Ozone Monitoring Networks as Global Baseline Networks of GCOS. (2007), GCOS AOPCXIII, Doc. no. 25, 18 April 2007, Revised version 29 August 2007, 24 pp.

Iqbal M. (1983). An introduction to solar radiation, Acad. Press, 101.

Kaufman Y. (1993), Aerosol optical thickness and atmospheric path radiance, J. Geophys. Res., 98, 2677-2692.

Kasten F., Young A. T. (1989). Revised optical air mass tables and approximation formula Applied Optics 28 (22), 4735-4738.

Kneizys F.X., Shettle E.P., Gallery W.O., Chetwynd J.H., Abreu L.W., Selby J.E.A., Fenn R.W., McClatchey R.A. (1980). Atmospheric transmittance/radiance: Computer Code LOWTRAN 5, Tech. Rep. AFGL-TR-80-0067 USAF Geophysics Laboratory, Hanscom AFB, MA. 
Koepke P., Quenzel H. (1979). Turbidity of the atmosphere determined from satellite: Calculation of optimum viewing geometry, J. Geophys. Res., 84, 7847-7856.

Krężel A. (1985). Solar radiation at the Baltic Sea surface, Oceanologia, 21, 5-32.

Krężel A, Kozłowski Ł. (2001). Verification of the model of a solar energy radiation input to the sea surface against actinometric data, Oceanol.Stud., 30, 3-4, 17-38.

Krężel A., Kozłowski Ł., Paszkuta M. (2008). A simple model of light transmission through the atmosphere over the Baltic Sea utilising satellite data, Oceanologia, 50 (2), 125-146.

Leckner B. (1978). The spectral distribution of solar radiation at the earth's surface-elements of a model, Sol. Energy, 20, 143-150.

Michalsky J.J. (1988). The astronomical Almanac's algorithm for approximate solar position (1950-2050). Solar Energy, 40 (3), 227-235.

Moradizadeh M., Momeni M., Saradjian M.R. (2008). Estimation of atmospheric column and near surface water vapor content using the radiance values of MODIS, The International Archives of the Photogrammetry, Remote Sensing and Spatial Information Sciences. Vol. XXXVII. Part B8. Beijing 2008, 523-528.

Neckel H., Labs D. (1981). Improved data of solar spectral irradiance from 0.33 to $1.25 \mathrm{~mm}$, Solar Phys., 74, 231-249.

Neuendorffer A.C. (1996). Ozone monitoring with TIROS-N operational vertical sounders, J. Geophys. Res., 101, D13, 18807-18828.

Reitan G.H. (1960). Mean monthly values of precipitable water over the United States, Month. Weath. Rev., 88, 25-35.

Sobrino J.A., Jiménez J.C., Raissouni N., Sòria G. (2002). A simplified method for estimating the total water vapor content over sea surfaces using NOAA-AVHRR channels 4 and 5, IEEE Transactions on Geoscience and Remote Sensing, 40, 357-361.

Sobrino J.A., Kharraz J.El. (2003). Surface temperature and vapor retrieval from MODIS data, Int. J. Remote Sensing, 24, 24, 5161-5182.

Sobrino J. A., Romaguera M. (2008). Water-vapour retrieval from Meteosat 8/SEVIRI observations, Int. J. Remote Sensing, 29, 3, 741-754.

Stowe L.L., Ignatov A.M., Singh R.R. (1997). Development, validation, and potential enhancements to the second-generation operational aerosol product at the National Environmental Satellite, Data, and Information Service of the National Oceanic and Atmospheric Administration, J. Geophys. Res., 102, D14, 16923-16934.

Tahl S., von Schoenermark M. (1998). Determination of the column water vapour of the atmosphere using backscattered solar radiation measured by the Modular Optoelectronical Scanner (MOS). Int. J. Remote Sensing, 19, 3223-3236.

TOMS. (2007). http://toms.gsfc.nasa.gov/ozone/ozoneother.html.

Walton C.C., Pichel W.G., Sapper J.F., May D.A. (1998). The development and operational application of nonlinear algorithms for the measurement of sea surface temperatures with the NOAA polar-orbiting environmental satellites, J. Geophys. Res., 103, C12, 27999-28012, doi:10.1029/98JC02370.

WMO. (1975). Manual on the observation of clouds and other meteors. WMO Publication 407, 155 pp. 


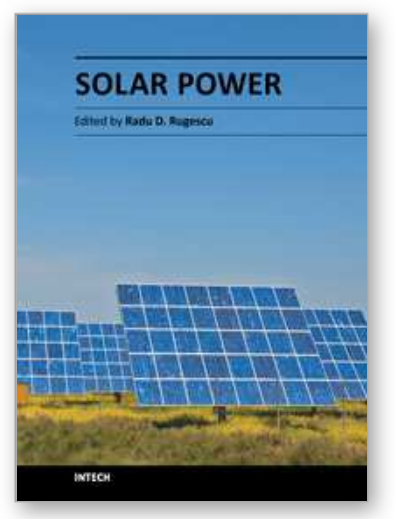

\section{Solar Power}

Edited by Prof. Radu Rugescu

ISBN 978-953-51-0014-0

Hard cover, 378 pages

Publisher InTech

Published online 15, February, 2012

Published in print edition February, 2012

A wide variety of detail regarding genuine and proprietary research from distinguished authors is presented, ranging from new means of evaluation of the local solar irradiance to the manufacturing technology of photovoltaic cells. Also included is the topic of biotechnology based on solar energy and electricity generation onboard space vehicles in an optimised manner with possible transfer to the Earth. The graphical material supports the presentation, transforming the reading into a pleasant and instructive labor for any interested specialist or student.

\section{How to reference}

In order to correctly reference this scholarly work, feel free to copy and paste the following:

Adam Krężel and Katarzyna Bradtke (2012). Estimation of Solar Energy Influx to the Sea in the Light of Fast Satellite Technique Development, Solar Power, Prof. Radu Rugescu (Ed.), ISBN: 978-953-51-0014-0, InTech, Available from: http://www.intechopen.com/books/solar-power/estimation-of-solar-energy-influx-to-the-sea-inthe-light-of-fast-satellite-technique-development

\section{INTECH}

open science | open minds

\section{InTech Europe}

University Campus STeP Ri

Slavka Krautzeka 83/A

51000 Rijeka, Croatia

Phone: +385 (51) 770447

Fax: +385 (51) 686166

www.intechopen.com

\section{InTech China}

Unit 405, Office Block, Hotel Equatorial Shanghai

No.65, Yan An Road (West), Shanghai, 200040, China

中国上海市延安西路65号上海国际贵都大饭店办公楼 405 单元

Phone: +86-21-62489820

Fax: +86-21-62489821 
(C) 2012 The Author(s). Licensee IntechOpen. This is an open access article distributed under the terms of the Creative Commons Attribution 3.0 License, which permits unrestricted use, distribution, and reproduction in any medium, provided the original work is properly cited. 